\title{
Effects of kinesiotaping on knee osteoarthritis: a literature review
}

\author{
Maryam Abolhasani ${ }^{1,2}$, Farzin Halabchi' ${ }^{1,2}$, Elahe Afsharnia', Vahideh Moradi ${ }^{3}$, Lee Ingle ${ }^{4}$, Ardalan Shariat', Azadeh Hakakzadeh ${ }^{1,2, *}$ \\ ${ }^{1}$ Sports Medicine Research Center, Neuroscience Institute, Tehran University of Medical Sciences, Tehran, Iran \\ ${ }^{2}$ Department of Sports and Exercise Medicine, School of Medicine, Tehran University of Medical Sciences, Tehran, Iran \\ ${ }^{3}$ Department of Orthotics and Prosthetics, Faculty of Rehabilitation Sciences, Iran University of Medical Sciences, Tehran, Iran \\ ${ }^{4}$ Department of Sport, Health \& Exercise Science, University of Hull, Kingston-upon-Hull, UK
}

The purpose of this review was to determine the current evidence-base for the efficacy of kinesiotaping in patients with osteoarthritis. Searching was undertaken using MEDLINE, Embase, Scopus, Web of Science, Physiotherapy Evidence Database (PEDro) from 2007 to 2018. The target terms included within our search criteria were "kinesiotape," "osteoarthrites," "knee pain," "adults," and "geriatric." Current findings indicate that kinesiotaping can be considered a useful method for decreasing pain without any side effects in patients with osteoarthritis. The search yielded 1,062 articles and finally seven studies met inclusion criteria. However, there are a limited number of appropriately powered, robustly designed studies. Further research is required to fully understand the short- and longer-term impact of kinesotaping in patients with osteoarthritis.

Keywords: Kinesiotaping, Osteoarthritis, Knee, Rehabilitation

\section{INTRODUCTION}

Considered as a major public health concern within our modern society, osteoarthritis $(\mathrm{OA})$ is a common disorder and fundamental cause of loss of function in the old people. OA is the most common form of degenerative joint disease affecting $15 \%-40 \%$ of people over 40 years of age (White and Waterman, 2012). Every one hundred fifty individuals out of one million suffer from $\mathrm{OA}$ worldwide; therefore, it is ranked as the sixth major cause of moderate and severe disability. The prevalence and incidence of knee $\mathrm{OA}$ is ten times greater in patients between 30-65 years than in younger patients, indicating it is a disease mainly associated with the aging process. Approximately $80 \%$ of patients with knee OA suffer from some form of movement restriction, and $20 \%$ are unable to perform basic daily activities; indeed, $11 \%$ of sufferers require personal care (Bhatia et al., 2013). Amongst the cardinal symptoms of $\mathrm{OA}$, pain is the biggest concern, and motor disability and impaired proprioception are important secondary factors
(Burks, 2002).

Treatment options for knee OA are divided into three categories: drug therapy, surgery, and rehabilitation. Drug therapy in the form of anti-inflammatory drugs are commonly used by patients, but these may be associated with complications (Sawitzke et al., 2010). Surgical options include gel injections and joint replacements, however, these are very costly and are associated with complications (Chang et al., 1993). Therefore, rehabilitation techniques, which are relatively low cost, are a popular treatment option in order to improve quality of life, improve range of motion, and reduce pain in patients with knee OA.

Clinical practice (therapy), acupuncture, aqua therapy, laser therapy and kinesiotaping (KT) are all routinely used to treat patients with knee OA (McAlindon et al., 2014). KT increases muscle flexibility and muscle strength, whilst improving the proprioception in patients with various musculoskeletal disorders (Akbaş et al., 2011; Williams et al., 2012); tapes are divided into two categories: elastic and nonelastic. The elastic group includes KT
${ }^{*}$ Corresponding author: Azadeh Hakakzadeh (iD https://orcid.org/0000-0003-2024-2712 Sports Medicine Research center, Neuroscience Institute, Tehran University of Medical Sciences, Tehran 11489, Iran

E-mail: ahakakzade@yahoo.com

Received: June 1, 2019 / Accepted: July 10, 2019
This is an Open Access article distributed under the terms of the Creative Commons Attribution Non-Commercial License (http://creativecommons.org/licenses/by-nc/4.0/) which permits unrestricted non-commercial use, distribution, and reproduction in any medium, provided the original work is properly cited. 
which has a thickness and elasticity similar to that of the skin; it is analgesic, made of linen, and known by different names. Taping principles were first introduced in Japan and Korea in 1970. Since then, various methods have been proposed and developed. Various mechanisms for the effective use of KT have been proposed including 'lifting' which is associated with the adhesive and elastic properties of $\mathrm{KT}$ as the amount of inter-tissue space increases improving blood and lymph circulation (Campolo et al., 2013). 'Gate-control of pain': The pain intensity reduces due to the stimulation of mechanical receptors of the skin. Finally, 'neurofacilitation' is the stimulation of skin mechanoreceptors causing positive changes to the nervous system.

\section{MATERIALS AND METHODS}

For identifying relevant articles, electronic databases including of MEDLINE, Embase, Scopus, Web of Science and the Cochrane Review (Shariat et al., 2019) were searched between 2007 to 2018. Databases were searched with the following keywords: "kinesiotape," "osteoarthrites," "knee pain," "adults," and "geriatric." Moreover, reference lists of the included studies and relevant con- ference papers were checked. Two researchers evaluated all included articles to identify the appropriate studies. In the final stage, articles were eligible if they met the following criteria:

(a) Studies which examined the effects of KT on OA of the knee.

(b) Only clinical trials were included (systematic reviews and meta-analyses were excluded).

(c) The study population had no history of knee surgery.

(d) Studies were published in English language only.

\section{RESULTS}

The search of databases provided 1,062 papers. Fig. 1. displays the process of selecting the studies. After removing irrelevant studies, we identified seven eligible studies from 2008 to 2018 that reported the effect of KT on knee OA. Retrieved data are presented in Table 1 . All of the relevant studies were randomized control trials. The studies' sample size was between 22-61 and age range was 22-70 years. In five studies, authors reported the grade of OA. In two studies the grade of OA was not reported (Aytar et al., 2011; Cho et al., 2015). Visual analogue scales were

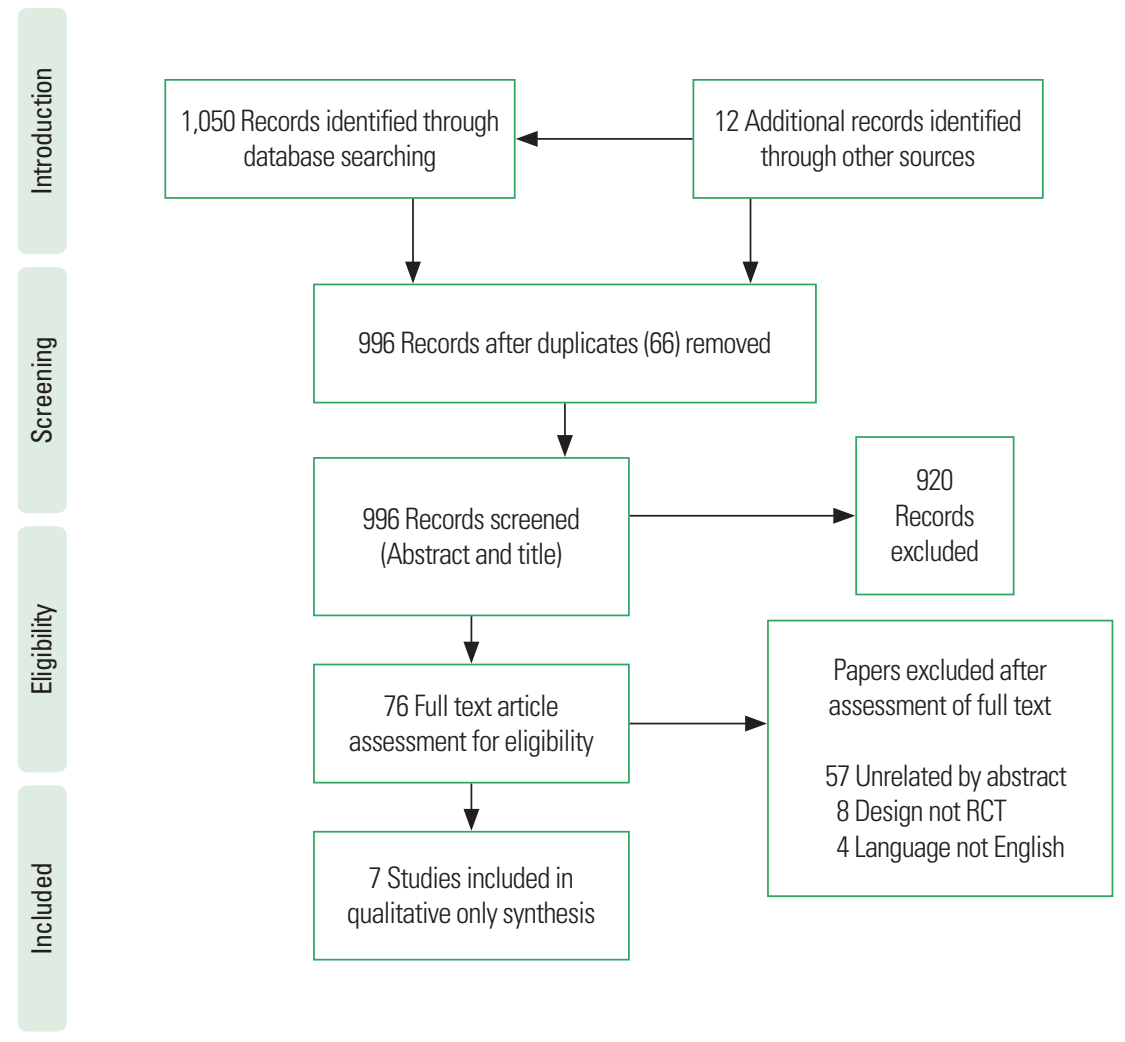

Fig. 1. Process of selecting the study. RCT, randomized controlled trial. 
Table 1. Summary of included trials $(n=7)$

\begin{tabular}{|c|c|c|c|c|c|}
\hline No & Study & Title & Study design & Methods & Conclusion \\
\hline 1 & Cho et al. (2015) & $\begin{array}{l}\text { KT improves pain, range of motion, } \\
\text { and proprioception in older } \\
\text { patients with knee osteoarthritis }\end{array}$ & RCT & $\begin{array}{l}\text { Sample size: } \mathrm{N}=46 \text { (patients with knee } \mathrm{OA} \text { ) } \\
\text { Age (yr): } \mathrm{G} 1,58.2 \text { (4.5); G2, } 57.5 \text { (4.4) } \\
\text { Intervention: } \mathrm{G1}, \mathrm{KT} ; \mathrm{G} 2 \text {, placebo KT } \\
\text { Duration: } 60 \text { min (taping) }\end{array}$ & $\begin{array}{l}\text { KT has reduced pain and } \\
\text { improved AROM and } \\
\text { proprioception in osteoarthritis } \\
\text { subjects. }\end{array}$ \\
\hline 2 & Aytar et al. (2011) & $\begin{array}{l}\text { Initial effects of KT in patients with } \\
\text { patellofemoral pain } \\
\text { syndrome }\end{array}$ & RCT & $\begin{array}{l}\text { Sample size: } \mathrm{N}=22 \text { (patients with PFPS) } \\
\text { Age (yr): } \mathrm{G} 1,22.41 \pm 1.62 ; \mathrm{G} 2,26.20 \pm 3.52 \\
\text { Intervention: } \mathrm{G1}, \mathrm{KT} ; \mathrm{G} 2 \text {, placebo KT }\end{array}$ & $\begin{array}{l}\text { KT has not reduced the excited } \\
\text { movement pain (followed by } \\
\text { walking). }\end{array}$ \\
\hline 3 & $\begin{array}{l}\text { Anandkumar et al. } \\
\text { (2014) }\end{array}$ & $\begin{array}{l}\text { Efficacy of KT on isokinetic } \\
\text { quadriceps torque in knee } \\
\text { osteoarthritis: a double blinded } \\
\text { randomized controlled study }\end{array}$ & RCT & $\begin{array}{l}\text { Sample size: } N=40 \text { (patients with knee } 0 A \text {, grade } 1-4 \text { ) } \\
\text { Age (yr): } G 1,55.7 \pm 5.8 ; G 2,55.9 \pm 5.0 \\
\text { Intervention: } G 1 \text {, therapeutic } K T ; G 2 \text {, sham KT }\end{array}$ & $\begin{array}{l}\text { Application of therapeutic KT is } \\
\text { effective in improving isokinetic } \\
\text { quadriceps torque, reducing } \\
\text { pain in knee osteoarthritis. }\end{array}$ \\
\hline 4 & Mutlu et al. (2017) & $\begin{array}{l}\text { Does KT of the knee improve pain } \\
\text { and functionality in patients with } \\
\text { knee osteoarthritis?: a } \\
\text { randomized controlled clinical } \\
\text { trial }\end{array}$ & RCT & $\begin{array}{l}\text { Sample size: } N=42 \text { (participants with knee } 0 A \text {, grade 2-4) } \\
\text { Age (yr): } G 1,54.25 \text { (6.01); } G 2,57.10 \text { (6.26) } \\
\text { Intervention: } G 1, K T ; G 2 \text {, placebo KT } \\
\text { Duration: } 12 \text { to } 16 \text { days }\end{array}$ & $\begin{array}{l}\text { KT resulted in superior } \\
\text { short-term effects on walking } \\
\text { task, pain, and knee-flexion } \\
\text { ROM compared with placebo } \\
\text { taping. }\end{array}$ \\
\hline 5 & Kocyigit et al. (2015) & $\begin{array}{l}\text { KT or sham taping in knee } \\
\text { osteoarthritis? A randomized, } \\
\text { double-blind, sham-controlled } \\
\text { trial }\end{array}$ & RCT & $\begin{array}{l}\text { Sample size: } N=43 \\
\text { Age (yr): } G 1 \text {, range } 40-70 \text { years; } G 2,32-70 \text { years } \\
\text { Intervention: } G 1, K T ; G 2 \text {, Sham KT }\end{array}$ & $\begin{array}{l}\text { Inconclusive evidence of a } \\
\text { beneficial effect of KT over } \\
\text { sham taping in knee } \\
\text { osteoarthritis. }\end{array}$ \\
\hline 6 & Öğüt et al. (2018) & $\begin{array}{l}\text { Does KT improve muscle strength } \\
\text { and function in knee osteoarthritis }\end{array}$ & RCT & $\begin{array}{l}\text { Sample size: } \mathrm{N}=61 \text { (females with knee } \mathrm{OA} \text {, grade } 2 \text { or } 3 \text { ) } \\
\text { Age (yr): G1, 53.8 } \pm 3.5 ; \mathrm{G} 2,53.1 \pm 3.6 \\
\text { Intervention: G1, KT-hot pack ( } 30 \text { min)+ultrasound (10 min)+ } \\
\text { TENS ( } 30 \text { min); G2, Sham KT-hot pack (30 min)+ } \\
\text { ultrasound (10 min)+TENS ( } 30 \text { min) } \\
\text { Duration: G1, } 1 \text { time/wk for 3rd weeks; G2, } 1 \text { time/wk for } \\
\text { 3rd weeks }\end{array}$ & $\begin{array}{l}\text { KT in women with knee } 0 A \\
\text { seems to be effective in } \\
\text { reducing pain and increasing } \\
\text { physical capacity. }\end{array}$ \\
\hline 7 & $\begin{array}{l}\text { Castrogiovanni et al. } \\
\text { (2016) }\end{array}$ & $\begin{array}{l}\text { The effects of exercise and KT on } \\
\text { physical limitations in patients } \\
\text { with knee OA }\end{array}$ & RCT & $\begin{array}{l}\text { Sample size: } \mathrm{N}=66 \text { (patients with knee } \mathrm{OA}, 2 \text { and } 3 \text { ) } \\
\text { Age (yr): } \mathrm{G1}, 63.90 \pm 15.4 ; \mathrm{G} 2,64.20 \pm 14.5 ; \mathrm{G}, 64.80 \pm 14.2 \\
\text { Intervention: } \mathrm{G1} \text {, exercise group; } \mathrm{G} 2 \text {, exercise KT with } \\
\text { tension; } \mathrm{G} 3 \text {, exercise KT without tension }\end{array}$ & $\begin{array}{l}\text { KT with a moderate exercise is } \\
\text { an effective way of managing } \\
\text { pain and motor limitations in } \\
\text { patients with knee OA. }\end{array}$ \\
\hline
\end{tabular}

KT, kinesio taping; ROM, range of motion; OA, osteoarthritis; AROM, active range of motion; PFPS, patellofemoral pain syndrome; TEP, traditional exercise program; ST, sensory motor training; TENS, transcutaneous electrical nerve stimulation; G, group; RCT, randomized controlled trial.

used for assessing pain in the studies. In four studies the short-term effect of KT was evaluated (Anandkumar et al., 2014; Aytar et al., 2011; Castrogiovanni et al., 2016; Cho et al., 2015), but in other studies, the effects of KT over time were reported (Kaya Mutlu et al., 2017; Kocyigit et al., 2015; Öğüt et al., 2018). Table 1 summaries these findings.

The effect of KT on pain was evaluated in all studies. Six studies reported that using KT lead to pain reduction in patients with OA, but in one study, KT was not effective for pain reduction (Aytar et al., 2011). Two studies reported the effect of KT on proprioception (Aytar et al., 2011; Cho et al., 2015). Aytar et al. (2011) showed there was no relationship between $\mathrm{KT}$ and increased proprioception. However, Cho et al. (2015) indicated that KT improved proprioception. AROM in the knee was examined in two studies (Cho et al., 2015; Kaya Mutlu et al., 2017). Findings showed that using $\mathrm{KT}$ increased AROM. An evaluation of quadriceps torque in one study suggested that KT compared with placebo KT significantly improved this variable (Anandkumar et al., 2014).

The current evidence-base for the positive impact of $\mathrm{KT}$ as an effective rehabilitation tool is mixed. This indicates the need for cutting edge review articles which have synthesized the latest evidence. The variation in the use of elastic tapes including coverage, elasticity, and timing makes it difficult to compare different studies and make informed conclusions. In examining the effect of KT on muscle electromyography activity, KT seems to be effective; however, this effect varies between different muscle groups due to muscle anatomy and the volume and sensitivity of skin receptors over the muscle and fascia (Cho et al., 2015). Most studies investigating electromyography activity have performed their investigations in the quadriceps muscle (Anandkumar et al., 2014; Aytar et al., 2011; Castrogiovanni et al., 2016).

A study conducted by Stauffer et al. (2011) the pain during rest 
after applying KT in knee OA patients has been investigated. This type of pain does not seem to restrict the patient's action, but provides discomfort. The use of KT decreased the above mentioned discomfort; nevertheless, it seems to make little significant clinical improvement in patients with $\mathrm{OA}$ and its effect was not very different from sham KT (Stauffer et al., 2011). A study performed by Cho et al. (2015), indicated that the pain during rest was not significantly different between the two groups of sham taping and KT; however, pain after walking was significantly decreased in the KT intervention group (Cho et al., 2015).

The results of this study, done by Aytar et al. (2011) are different from previous study, which show that the KT program in patients with patellofemoral pain syndrome does not effectively reduce pain (following walking). The results of these two studies cannot be compared because of the differences in the disease and the age of the patients. The range of joint range of motion in the study of Cho et al. (2015) was $21 \%$ and significantly improved in KT intervention group. Previous studies have shown that improving the joint range of motion is feasible following a KT intervention (González-Iglesias et al., 2009). The range of motion in different axes has increased after the KT treatment, and sham taping in both studies has been effective in improving the active range of motion. The use of KT in the study of Cho et al. (2015) not only reduced pain while walking, but also effectively improved the deep sense at three angles which has been similar to previous studies in this field. As in the study of Shakoor et al. (2008), KT with 8 weeks of exercise at home improves the deep sense of perception in patients. Kaya Mutlu et al. (2017) also placed patients with OA under 3-time KT within a month, which showed they had less pain and improved during walking than the group which received usual care. According to the nonhomogeneous results of current studies, we explored the effect of $\mathrm{KT}$ in patients with knee OA.

In 2014, Anandkumar et al. in their study determined the efficacy of $\mathrm{KT}$ on isokinetic quadriceps torque in patients with OA. Such as other studies, their results confirmed the positive effects of $\mathrm{KT}$ of reducing the level of pain and improving the isokinetic quadriceps torque. In 2015, Kocyigit et al. confirmed the significant effects of KT of level of pain measured by visual analogue scale (VAS). They also showed a significant improvement in Nottingham Health Profile in experimental group who received KT.

In 2016, Kaya Mutlu et al. randomized 42 patients into two groups. KT was applied to the quadriceps and hamstring muscles in three steps, and between every application of KT there were 3to 4-day intervals. Patients in the case group showed a significant reduction in VAS and walking task score compared to controls from the initial taping to the third taping. The case group in this study showed a short-term improvement in VAS during the night and the range of knee joint activity after a 1-month follow-up period. In this study, no significant difference was observed between the results of joint motion and muscle strength between the two groups. This study showed that the effect of KT can improve short-term improvement on walking task, knee joint pain and flexion in case group patients compared to control group.

In 2018, Öğüt et al. randomized 61 middle-aged women into two groups. Both groups received transcutaneous electrical nerve stimulation for $30 \mathrm{~min}$, hot pack for $30 \mathrm{~min}$, and ultrasound therapy for $10 \mathrm{~min}$ per day for 3 weeks ( 5 days a week). Also, one group (31 patients) was treated by KT and exercise was recommended for all patients. Home exercises for strengthening the knee muscles were also recommended. There was a significant improvement in the first month after treatment in VAS of the case group compared to controls. For the Western Ontario and McMaster Universities Osteoarthritis Index (WOMAC) and WOMAC total score intervention group after treatment, there was a significant decrease in both groups. In both WOMAC groups, the stiffness, physical performance, and overall values of the measured case showed a significant reduction. In both groups, the peak torque value measured in the quadriceps muscle was significantly increased after treatment. In conclusion, applying KT in women with knee $\mathrm{OA}$ seems to be effective in reducing pain and increasing physical capacity (Öğüt et al., 2018).

Castrogiovanni et al. (2016) investigated the effects of exercise and $\mathrm{KT}$ on physical limitations in patients with knee $\mathrm{OA}$, at the end of the study, only 57 people remained. Patients were randomly divided into three treatment groups. Group 1: exercise group, group 2: exercise group with KT applied with tension; group III: Exercise with KT not applied with tension. Knee pain decreased and knee joint function improved. Patients treated with KT and exercise required less analgesic use for at least one quarterly period. As a result, the authors claimed that KT therapy of the knee joint in conjunction with moderate exercise is an effective way of managing pain and motor limitations in patients with knee $\mathrm{OA}$ (Castrogiovanni et al., 2016).

In a meta-analysis conducted in 2018 which examined the improvements in pain and physical activity in patients with knee OA following the use of KT. The analysis of the results showed that there were a significant improvement in the pain index, VAS, WOMAC and range of motion among the 308 patients who were included in the study and received KT. Due to the limited clinical evidence of existing studies and low scientific strength, they as- 


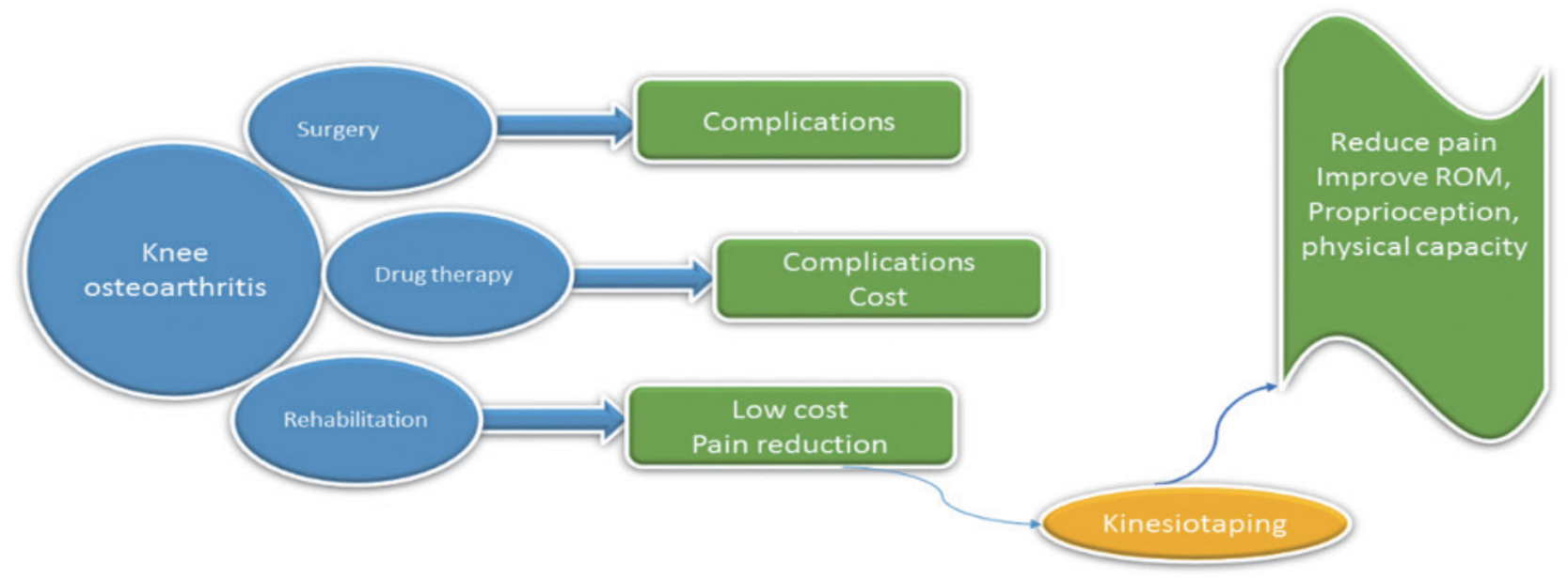

Fig. 2. Summary of study. ROM, range of motion.

sign the recommendation of the use of KT to a clinical decision based on patient needs (Lu et al., 2018). All of those mentioned studies confirmed the positive effect of KT on OA (Fig. 2), but the positive effects are not categorized based on the age and also there is no category based on the duration of treatment as it is very important to have a long-term follow-up.

\section{CONCLUSIONS}

Most studies have been conducted in people under the age of 30 years, and it is not clear whether the same effect is observed in older patients. The impact of KT with increasing age is currently unclear. For example, does the change in skin texture and structure associated with the aging process affect the impact of $\mathrm{KT}$ is unknown. In most studies, the participants were apparently healthy individuals and there are relatively few studies on clinical populations. Lack of standardization of the type of tape used, adhesive qualities, tape thickness, positioning, and duration of application mean that it is difficult to judge the effectiveness of KT in patients with $\mathrm{OA}$.

\section{CONFLICT OF INTEREST}

No potential conflict of interest relevant to this article was reported.

\section{ACKNOWLEDGMENTS}

This study was supported and approved by Tehran University of Medical Sciences (reference number: IR.TUMS.IKHC.REC.
1395.380).

\section{REFERENCES}

Akbaş E, Atay AO, Yüksel I. The effects of additional kinesio taping over exercise in the treatment of patellofemoral pain syndrome. Acta Orthop Traumatol Turc 2011;45:335-341.

Anandkumar S, Sudarshan S, Nagpal P. Efficacy of kinesio taping on isokinetic quadriceps torque in knee osteoarthritis: a double blinded randomized controlled study. Physiother Theory Pract 2014;30:375383.

Aytar A, Ozunlu N, Surenkok O, Baltacı G, Oztop P, Karatas M. Initial effects of kinesior taping in patients with patellofemoral pain syndrome: A randomized, double-blind study. Isokinet Exerc Sci 2011;19:135-142.

Bhatia D, Bejarano T, Novo M. Current interventions in the management of knee osteoarthritis. J Pharm Bioallied Sci 2013;5:30-38.

Burks K. Health concerns of men with osteoarthritis of the knee. Orthop Nurs 2002;21:28-34.

Campolo M, Babu J, Dmochowska K, Scariah S, Varughese J. A comparison of two taping techniques (kinesio and mcconnell) and their effect on anterior knee pain during functional activities. Int J Sports Phys Ther 2013;8:105-110.

Castrogiovanni P, Di Giunta A, Guglielmino C, Roggio F, Romeo D, Fidone F, Imbesi R, Loreto C, Castorina S, Musumeci G. The effects of exercise and kinesio tape on physical limitations in patients with knee osteoarthritis. J Func Morph Kinesio 2016;1:355-368.

Chang RW, Falconer J, Stulberg SD, Arnold WJ, Manheim LM, Dyer AR. A randomized, controlled trial of arthroscopic surgery versus closedneedle joint lavage for patients with osteoarthritis of the knee. Arthritis Rheum 1993;36:289-296. 
Cho HY, Kim EH, Kim J, Yoon YW. Kinesio taping improves pain, range of motion, and proprioception in older patients with knee osteoarthritis: a randomized controlled trial. Am J Phys Med Rehabil 2015;94:192200.

González-Iglesias J, Fernández-de-Las-Peñas C, Cleland JA, Huijbregts P, Del Rosario Gutiérrez-Vega M. Short-term effects of cervical kinesio taping on pain and cervical range of motion in patients with acute whiplash injury: a randomized clinical trial. J Orthop Sports Phys Ther 2009;39:515-521.

Kaya Mutlu E, Mustafaoglu R, Birinci T, Razak Ozdincler A. Does kinesio taping of the knee improve pain and functionality in patients with knee osteoarthritis?: a randomized controlled clinical trial. Am J Phys Med Rehabil 2017;96:25-33.

Kocyigit F, Turkmen MB, Acar M, Guldane N, Kose T, Kuyucu E, Erdil M. Kinesio taping or sham taping in knee osteoarthritis? A randomized, double-blind, sham-controlled trial. Complement Ther Clin Pract 2015; 21:262-267.

$\mathrm{Lu}$ Z, Li X, Chen R, Guo C. Kinesio taping improves pain and function in patients with knee osteoarthritis: A meta-analysis of randomized controlled trials. Int J Surg 2018;59:27-35.

McAlindon TE, Bannuru RR, Sullivan MC, Arden NK, Berenbaum F, Bierma-Zeinstra SM, Hawker GA, Henrotin Y, Hunter DJ, Kawaguchi H, Kwoh K, Lohmander S, Rannou F, Roos EM, Underwood M. OARSI guidelines for the non-surgical management of knee osteoarthritis. Osteoarthritis Cartilage 2014;22:363-388.

Ögüt H, Güler H, Yildizgören MT, Velioğlu O, Turhanoğlu AD. Does kinesiology taping improve muscle strength and function in knee osteoarthritis? a single-blind, randomized and controlled study. Arch Rheu- matol 2018;33:335-343.

Sawitzke AD, Shi H, Finco MF, Dunlop DD, Harris CL, Singer NG, Bradley JD, Silver D, Jackson CG, Lane NE, Oddis CV, Wolfe F, Lisse J, Furst DE, Bingham CO, Reda DJ, Moskowitz RW, Williams HJ, Clegg DO. Clinical efficacy and safety of glucosamine, chondroitin sulphate, their combination, celecoxib or placebo taken to treat osteoarthritis of the knee: 2-year results from GAIT. Ann Rheum Dis 2010;69:14591464.

Shakoor N, Furmanov S, Nelson DE, Li Y, Block JA. Pain and its relationship with muscle strength and proprioception in knee OA: results of an 8-week home exercise pilot study. J Musculoskelet Neuronal Interact 2008;8:35-42.

Shariat A, Najafabadi MG, Ansari NN, Cleland JA, Singh MAF, Memari AH, Honarpishe R, Hakakzadeh A, Ghaffari MS, Naghdi S. The effects of cycling with and without functional electrical stimulation on lower limb dysfunction in patients post-stroke: a systematic review with meta-analysis. NeuroRehabilitation 2019;44:389-412.

Stauffer ME, Taylor SD, Watson DJ, Peloso PM, Morrison A. Definition of nonresponse to analgesic treatment of arthritic pain: an analytical literature review of the smallest detectable difference, the minimal detectable change, and the minimal clinically important difference on the pain visual analog scale. Int J Inflam 2011;2011:231926.

White PH, Waterman M. Making osteoarthritis a public health priority: several initiatives are placing this chronic illness on the national agenda. Orthop Nurs 2012;31:92-97.

Williams S, Whatman C, Hume PA, Sheerin K. Kinesio taping in treatment and prevention of sports injuries: a meta-analysis of the evidence for its effectiveness. Sports Med 2012;42:153-164. 